\title{
The importance analysis of urban rail transit traction energy consumption influencing factors based on grey correlation degree
}

\author{
Zhang Jiao, Li Xi \\ (Beijing subway operation technology centre of Beijing Subway Operation Co. Ltd. , Vehicle and \\ equipment technology department, Beijing 102208, China)
}

\begin{abstract}
Keywords: traction energy consumption; grey system; grey correlation theory; correlation degree; grey correlation degree analysis

Abstract. Through the analysis of urban rail transit train traction energy consumption system, the main influencing factor of the traction energy consumption can be determined, but its incomplete information, which is a typical grey system. This article according to grey relation theory, establish a urban rail transit traction energy consumption influence factors of grey relational analysis model, the grey correlation analysis on the influence factor of the correlation degree is calculated, then analyze the important degree of each affecting factor, and sorting.
\end{abstract}

\section{Introduction}

Grey system theory is on the methodology of system thinking and system thoughts concrete manifestation, the original scientific significance. It with "the partial information known, the partial information unknown" small sample, poor information of uncertainty system as the research object, mainly through the generation and development of some known information, extract valuable information, to achieve a correct description of system behavior, evolution rule and effective monitoring[1,2,3,4]. Grey system theory is the study of grey analysis, modeling, forecasting, decision-making and control theory[5,6,7], it puts the general system theory, information about control point of view and breaking the law to the society, economy and ecology, such as an abstract system, and combining with mathematical method, developed a set of solve the incomplete information system (namely) of gray system theory and method. Analysis of grey system theory with the role of social science and natural science communication, can be an abstract system of materialization, quantitative, model, and do the best.

As the correlation degree and correlation analysis of grey system theory foundation is one of the main content of the research and application of the grey system theory[8,9,10]. For factors between the two systems, the time or the size of the correlation of different objects and change measure, called the correlation degree [11,12]. Grey correlation analysis is based on various factors change curve geometric shape similarity degree, judging factors between correlation degree method, the basic idea is through the determination of reference sequence and several geometric shape similarity degree to judge whether the contact closely, it reflects the correlation degree of the curve.

\section{Grey correlation analysis steps}

(1) According to determine the evaluation index system of evaluation purpose. If $m$ sequence data form matrix as follows:

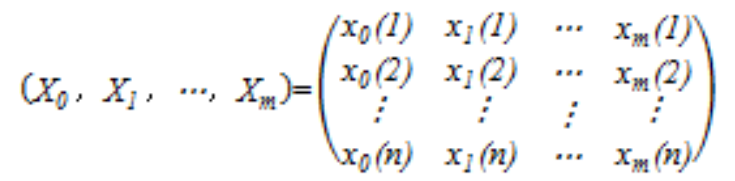

Where $\mathrm{n}$ is the number of indicators, factors affecting the behavior of the system become more sequence data sequence, consisting of notes for $\mathrm{x}_{\mathrm{i}}=\left(\mathrm{x}_{\mathrm{i}}(1), \mathrm{x}_{\mathrm{i}}(2), \ldots, \mathrm{x}_{\mathrm{i}}(\mathrm{n})\right)^{\mathrm{T}}, \mathrm{i}=1,2,3, \ldots, \mathrm{m}$.

(2) To determine the reference sequence (evaluation criteria)

According to the comparative sequence to determine the optimal index set as a reference, to remember $\mathrm{x}_{0}=\left\{\mathrm{x}_{0}(\mathrm{k}) \mid \mathrm{k}=1,2, \ldots, \mathrm{n}\right\}$. The optimal index set respectively to the components in the 
optimal value of index in the evaluation objects. If the index is positive polarity index, choose the maximum value of each evaluation index; If index is negative polarity index, select the minimum value.

(3) The parameter values of dimensionless processing

Due to various factors in the system data in a column may be due to the different dimensions, comparison, or in more difficult to get the correct conclusion, so the grey correlation analysis, generally for the dimensionless processing of data. Dimensionless processing method is based on the following two formulas the original indices $\mathrm{x}_{\mathrm{i}}(\mathrm{k})$ into a dimensionless value $\mathrm{x}_{\mathrm{i}}(\mathrm{k})$, which makes $\mathrm{x}_{\mathrm{i}}{ }^{\mathrm{r}}(\mathrm{k}) \in(0,1)$, Eq. (1) is suitable for normal polarity index, Eq. (2) is suitable for the negative polarity.

$$
\begin{aligned}
& x_{\mathrm{i}}^{\prime}(k)=\left[x_{\mathrm{i}}(k)-\min x_{\mathrm{i}}(k)\right] /\left[\max _{\mathrm{i}}(k)-\min x_{\mathrm{i}}(k)\right] \\
& x_{\mathrm{i}}^{b}(k)=\left[\max x_{i}(k)-x_{\mathrm{i}}(k)\right] /\left[\max _{i}(k)-\min x_{i}(k)\right]
\end{aligned}
$$

Type: $\operatorname{maxx}_{\mathrm{i}}(\mathrm{k})$ and $\operatorname{minx}_{\mathrm{i}}(\mathrm{k})$ respectively the maximum and the minimum of each reference object.

(4) Calculating grey correlation coefficient $\xi_{i}(\mathrm{k})$

Calculation formula is:

$$
\xi_{i}(k)=\frac{\Delta \min +\otimes \Delta \max }{\| x_{0}(k)-x_{i}(k) \mid+\Delta \Delta \max }
$$

In Eq. (3): $\Delta \min =\min \left|x_{0}(k)-x_{i}(k)\right|, \Delta \max =\max \left|x_{0}(k)-x_{i}(k)\right|$, respectively the maximum absolute value and the minimum absolute value of $x_{i}(k)$ and $x_{0}(k)$ and; $p$ is distinguish coefficient of 0.5 .

(5) Calculating the degree of correlation

The correlation is due to the correlation coefficient is a sequence and reference in the connection degree of each point value, so it is more than one, and information too scattered is not convenient to compare integrity, so it is necessary to each point of the correlation coefficient of concentration of a value, which is for the average, as compare sequence and the number of correlation degree between the reference sequence, said $r_{i}$ associated degree formula such as Eq. (4) :

(6) The degree of correlation sort

$$
r_{\mathrm{i}}=\frac{\mathbb{P}}{N} \sum_{\mathrm{N}=1}^{\mathrm{N}} \xi_{\mathrm{i}}(k)
$$

Correlation value according to the size of the order, if $r_{1}<r_{2}$, more similar to the reference sequence and compare sequence $\mathrm{x}_{2}$.

\section{Traction energy consumption influencing factors of importance degree sort}

Respectively determine the urban rail transit train traction energy consumption of various influencing factors of the corresponding indicators, specific results are shown in table 1. Due to a practical circuit of the circuit features (ramp, the curve radius) cannot be quantified data processing, and consider the train is fixed, so the grey correlation analysis indicators do not include the slope and curve radius and the train. Similarly, trains only consider the auxiliary energy consumption ratio of total traction energy consumption. In addition, because the length of the stop spacing is closely related to the station spacing, can approximate as part of the station spacing, so this article will stand average station spacing as a parking space and distance between the two factors affecting the common analysis indicators. 


\begin{tabular}{|c|c|}
\hline Influence factors & Analysis index \\
\hline $\begin{array}{c}\text { Train auxiliary } \\
\text { equipment }\end{array}$ & $\begin{array}{c}\text { Auxiliary power consumption accounted } \\
\text { for the proportion of total energy } \\
\text { consumption }\end{array}$ \\
\hline Station spacing & Average station spacing \\
\hline Stop spacing & Average station spacing \\
\hline Full load rate & Full load rate \\
\hline Design speed & Design speed \\
\hline Running speed & Average speed \\
\hline
\end{tabular}

Table 1 influence factors and the result of analysis indicators of choice

In this paper, by means of simulation the traction energy consumption and the indicators data, data from the simulation results are shown in table 2.

\begin{tabular}{|c|c|c|c|c|c|c|}
\hline & $\begin{array}{c}\text { Traction } \\
\text { energy } \\
\text { consumption } \\
\text { Kwh/(person } \\
\text { km })\end{array}$ & $\begin{array}{c}\text { The proportion } \\
\text { of air } \\
\text { conditioning } \\
\text { energy } \\
\text { consumption i } \\
\text { traction energy } \\
\text { consumption }\end{array}$ & $\begin{array}{c}\text { Desig } \\
\mathrm{n} \\
\text { speed } \\
\mathrm{km} / \mathrm{h}\end{array}$ & $\begin{array}{c}\text { Full } \\
\text { load } \\
\text { rate }\end{array}$ & $\begin{array}{c}\text { Average } \\
\text { speed } \\
\mathrm{km} / \mathrm{h}\end{array}$ & $\begin{array}{c}\text { Average } \\
\text { stop } \\
\text { spacing km }\end{array}$ \\
\hline 1 & 12.70 & 15.38 & 110 & 100 & 80.01 & 8.62 \\
\hline 2 & 15.14 & 14.81 & 105 & 90 & 77.53 & 6.03 \\
\hline 3 & 16.94 & 15.48 & 100 & 80 & 74.61 & 4.64 \\
\hline 4 & 19.98 & 15.63 & 95 & 70 & 71.67 & 3.77 \\
\hline 5 & 22.23 & 15.84 & 90 & 65 & 68.51 & 3.18 \\
\hline 6 & 24.92 & 16.01 & 85 & 60 & 65.62 & 2.74 \\
\hline 7 & 27.95 & 16.42 & 80 & 55 & 62.28 & 2.41 \\
\hline 8 & 31.33 & 17.12 & 75 & 50 & 58.64 & 2.16 \\
\hline
\end{tabular}

Table 2 the indicators and data simulation gains traction current consumption

Due to analyze the effect of various factors on the traction energy consumption of important degree, so the selection of the traction energy consumption as the reference sequence, the factors index as a comparative sequence. After the index dimensionless processing results which are shown in table 3. 


\begin{tabular}{|c|c|c|c|c|c|c|}
\hline & $\begin{array}{c}\text { Traction } \\
\text { energy } \\
\text { consumption } \\
\mathrm{x}_{0}\end{array}$ & $\begin{array}{c}\text { The proportion of } \\
\text { air conditioning } \\
\text { energy } \\
\text { consumption i } \\
\text { traction energy } \\
\text { consumption } \mathrm{x}_{1}\end{array}$ & $\begin{array}{c}\text { Desig } \\
\mathrm{n} \\
\text { speed } \\
\mathrm{x}_{2}\end{array}$ & $\begin{array}{c}\text { Full } \\
\text { load } \\
\text { rate } \\
\mathrm{x}_{\mathrm{a}}\end{array}$ & $\begin{array}{c}\text { Averag } \\
\text { e speed } \\
\mathrm{x}_{4}\end{array}$ & $\begin{array}{c}\text { Average } \\
\text { station } \\
\text { spacing } \mathrm{x}_{5}\end{array}$ \\
\hline 1 & 1.0000 & 0.7532 & 0 & 0 & 0 & 1.0000 \\
\hline 2 & 0.8690 & 1.0000 & $\begin{array}{c}0.142 \\
9\end{array}$ & $\begin{array}{c}0.20 \\
00\end{array}$ & 0.1160 & 0.5991 \\
\hline 3 & 0.7724 & 0.7100 & $\begin{array}{c}0.285 \\
7\end{array}$ & $\begin{array}{c}0.40 \\
00\end{array}$ & 0.2526 & 0.3839 \\
\hline 4 & 0.6092 & 0.6450 & $\begin{array}{c}0.428 \\
6\end{array}$ & $\begin{array}{c}0.60 \\
00\end{array}$ & 0.3901 & 0.2492 \\
\hline 5 & 0.4885 & 0.5541 & $\begin{array}{c}0.571 \\
4\end{array}$ & $\begin{array}{c}0.70 \\
00\end{array}$ & 0.5379 & 0.1579 \\
\hline 6 & 0.3441 & 0.4805 & $\begin{array}{c}0.714 \\
3\end{array}$ & $\begin{array}{c}0.80 \\
00\end{array}$ & 0.6731 & 0.0898 \\
\hline 7 & 0.1814 & 0.3030 & $\begin{array}{c}0.857 \\
1\end{array}$ & $\begin{array}{c}0.90 \\
00\end{array}$ & 0.8293 & 0.0387 \\
\hline 8 & 0 & 0 & $\begin{array}{c}1.000 \\
0\end{array}$ & $\begin{array}{c}1.00 \\
00\end{array}$ & 1.0000 & 0 \\
\hline
\end{tabular}

Table 3 data dimensionless processing results

According to table 3, calculate the corresponding number list, as shown in table 4 .

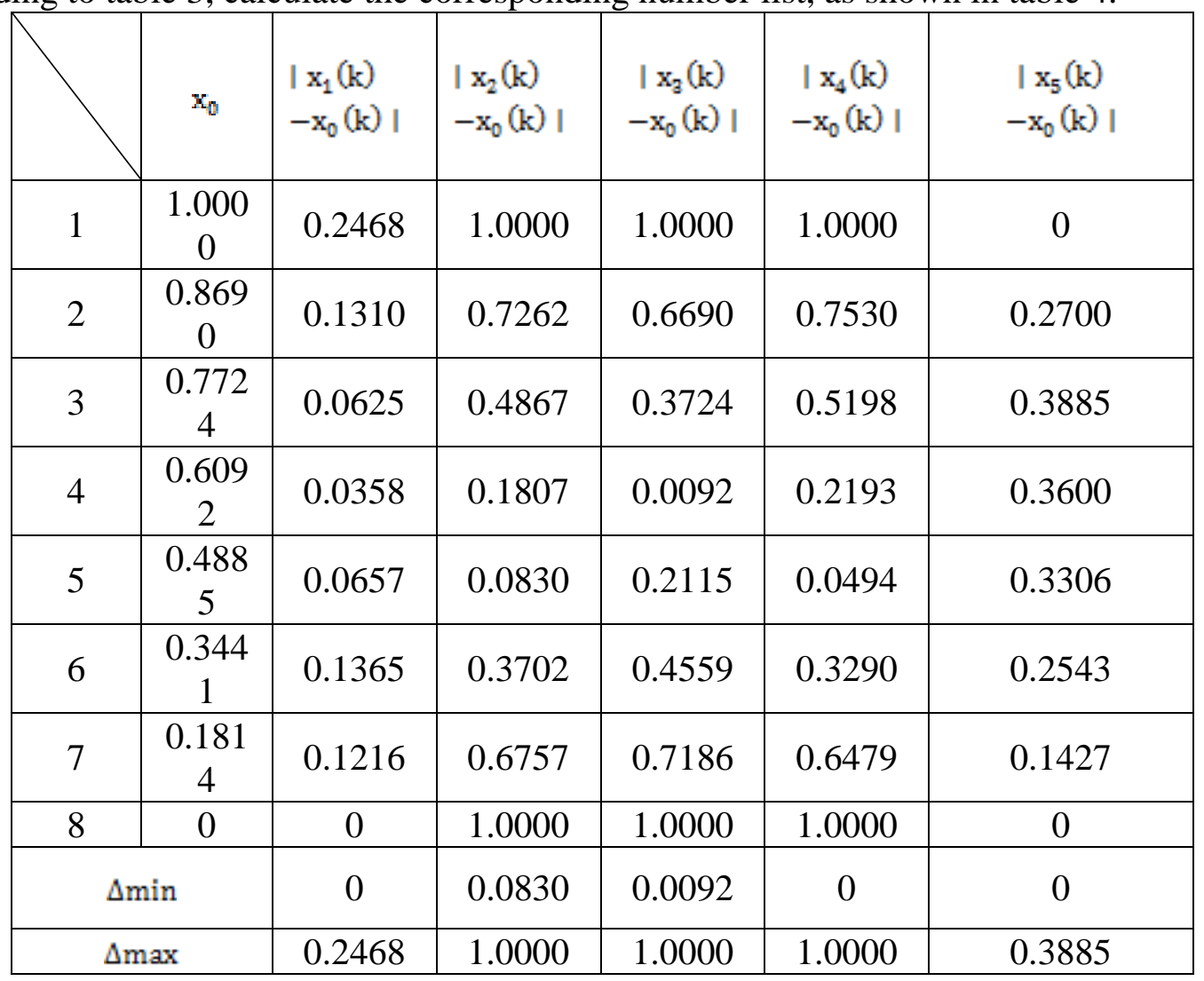

Table 4 corresponding differential list 
To $p=0.5$, calculate the correlation coefficient $\xi_{1}(\mathrm{k})$ is shown in table 5 .

\begin{tabular}{|c|c|c|c|c|c|}
\hline & $\xi_{\text {i1 }}$ & $\xi_{\text {i2 }}$ & $\xi_{\text {ij }}$ & $\xi_{\text {if }}$ & $\xi_{\text {i5 }}$ \\
\hline 1 & 0.3333 & 0.3887 & 0.3395 & 0.3663 & 1.0000 \\
\hline 2 & 0.4851 & 0.4755 & 0.4356 & 0.4385 & 0.4184 \\
\hline 3 & 0.6638 & 0.5909 & 0.5837 & 0.5387 & 0.3333 \\
\hline 4 & 0.7751 & 0.8565 & 1.0000 & 0.7639 & 0.3505 \\
\hline 5 & 0.6526 & 1.0000 & 0.7157 & 1.0000 & 0.3701 \\
\hline 6 & 0.4748 & 0.6700 & 0.5327 & 0.6627 & 0.4331 \\
\hline 7 & 0.5037 & 0.4959 & 0.4179 & 0.4786 & 0.5765 \\
\hline 8 & 1.0000 & 0.3887 & 0.3395 & 0.3663 & 1.0000 \\
\hline$r_{i}$ & 0.6110 & 0.6082 & 0.5456 & 0.5769 & 0.5602 \\
\hline
\end{tabular}

Table 5 association coefficient calculation results

\begin{tabular}{|c|c|c|}
\hline Serial number & Influence factors & Correlation degree \\
\hline 1 & $\begin{array}{c}\text { Train auxiliary } \\
\text { equipment }\end{array}$ & 0.611 \\
\hline 2 & Design speed & 0.6082 \\
\hline 3 & Full load rate & 0.5456 \\
\hline 4 & Running speed & 0.5769 \\
\hline 5 & $\begin{array}{c}\text { Station spacing, stop } \\
\text { spacing }\end{array}$ & 0.5602 \\
\hline
\end{tabular}

Table 6 the correlation between various influencing factors

Calculation results show that the urban rail transit train traction energy consumption influence factors of importance to include: the train auxiliary equipment $>$ design speed $>$ running speed $>$ station spacing $>$ Full load rate.

\section{Conclusion}

This article traction energy consumption and relevant influencing factors are obtained by simulation data, using the calculation method of grey correlation theory to deal with these data, calculate the correlation of various influencing factors. Study conclusion shows that the auxiliary equipment, the design speed, the speed train, station spacing, the full load rate are five factors that affect the correlation value is reduced, in turn, in accordance with the relevant classification, train auxiliary equipment and design speed is significantly influence factors, the other for general influencing factors.

\section{References}

[1] Liang G Ch,Zheng Y P,Pu H B. gray correlation analysis of optimized design for underground gas storage [J].Natural Gas Industry,2004,24(09):142-144 .

[2] Ma Y L,WangJY. Comprehensive evaluation of gray correlation analysis based on ideal plans [J].Journal of Systems Engineering and Electronics,2002,24(07):51-54 .

[3] Liu Sifeng. On measure of grey information [J].Journal of Grey System,1995,7(02):97-101 .

[4] MU Rui ZHANG Jia-tai. Research of hierarchy synthetic evaluation based on grey relational analysis [J]. Systems Engineering-Theory \& Practice,2008,28(10):142-144 .

[5] Deng Julong. Grey control system [M].Wuhan: Huazhong university of science press,1985 .

[6] Deng Julong. Basic method of grey system [M].Wuhan: Huazhong university of science press, 1987 . 
[7] Deng Julong. Grey theoretical foundation [M].Wuhan: Huazhong university of science and technology press, 2002.122-209 .

[8] Deng Julong. Grey theoretical foundation [M].Wuhan: Huazhong university of science and technology press, 2002.122-209.

[9] Luo Jun,Lv Tiansheng,Wang Qi. A Study on Comprehensive Evalua-tion for Products Design Quality Based on Grey System Theory [J]. Mechanical Science And Technology,2000,19(05):747-749

[10] Liu Sifeng,Guo Tianbang,Dang Yaoguo. Grey system theory and its application [M].Beijing: Science Press, 1999 .

[11] Wen K L. The grey system analysis and its application in gas breakdown and VAR compensator finding (Invited Paper) [J].International Journal of Computational Cognition,2004,2(01):21-44 .

[12] Chan J W K,Tong T K L. Multi-criteria material selections and end-of-life product strategy:Grey relational analysis approach [J].Materials \& Design,2007,28(05):1539-1546 . 